\title{
Meningitis bacteriana aguda por Streptococcus suis en criadores de cerdos: comunicación de los primeros dos casos en Chile
}

\author{
Erica Koch, Gino Fuentes, Rodrigo Carvajal, Ricardo Palma, Verónica Aguirre, \\ Carolina Cruz, Ruby Henríquez y Mario Calvo
}

\section{Streptococcus suis meningitis in pig farmers: report of first two cases in Chile}

Human infection by Streptococcus suis is a zoonosis with a known occupational risk. Meningitis is its most frequent clinical manifestation. We present the first two cases in Chile. First case: 54 -year-old female patient, pigfarmer. She presented headache, vomiting, confusion and meningismus. She presented septic shock. Second case: 48-year-old male patient, also pig farmer, presented headache, vomiting and meningismus. A Gram's staining of cerebrospinal fluid (CSF) showed gram-positive cocci in both cases. Ceftriaxone and dexamethasone treatment was administered. The CSF cultures were positive for Streptococcus suis serotype 2. The patients experienced a good outcome, without neurological sequelae at the time of discharge. It is considerable to evaluate epidemiologic factors in order to suspect this etiological agent in cases of meningitis. These cases enhance the need of heighten awareness of potential for occupational exposure and infection by this emerging human pathogen. Educating population at risk about simple preventive measures must be considered.

Key words: Streptococcus suis, meningitis.

Palabras clave: Streptococcus suis, meningitis.

(Artículos relacionados en páginas 539 y 554)

\section{Introducción}

$S$ treptococcus suis es un patógeno zoonótico en cerdos $^{1}$, siendo el serotipo 2 el más asociado a patogenicidad $^{2}$. La infección humana es conocidamente un riesgo ocupacional ${ }^{1,3}$, habiéndose descrito la mayoría de los casos en pacientes inmunocompetentes ${ }^{1}$. La meningitis aguda es la manifestación clínica más frecuente de la infección por este microorganismo ${ }^{4}$. Desde el primer caso reportado en Dinamarca en $1968^{5}$, más de 700 casos han sido documentados, procedentes en su mayoría del norte europeo y sur asiático ${ }^{6}$. Un brote ocurrido en China en julio de 2005, con 215 casos y 38 muertes, enfatiza la importancia de $S$. suis como una zoonosis emergente ${ }^{6}$, e incluso como una infección capaz de afectar a la población general. En Latinoamérica, la infección por S. suis ha sido mucho menos documentada, habiéndose publicado el primer caso en el año 2005 en Argentina ${ }^{7}$. En la presente comunicación, reportamos los dos primeros casos de infección humana por S. suis ocurridos en el sur de Chile.

\section{Caso clínico 1}

Mujer de 54 años de edad, con antecedentes de obesidad y tabaquismo, procedente de un sector rural. Acudió al consultorio de su localidad por un cuadro de dolor abdominal, vómitos y cefalea con dos días de evolución, donde le fue indicado un tratamiento sintomático. Posteriormente se agregó compromiso de conciencia y agitación psicomotora, por lo que consultó nuevamente en su centro de salud, siendo derivada a nuestro hospital. Al ingreso la paciente se encontraba taquicárdica, taquipneica, afebril y confusa. Al examen físico segmentario presentaba signos meníngeos; sin otros hallazgos importantes que destacar.

Los recuentos hematológicos realizados al ingreso demostraron una leucocitosis de 27.080 céls $/ \mathrm{mm}^{3}$; con 91,8\% de neutrófilos. La gasometría venosa mostró una acidosis metabólica. La proteína $\mathrm{C}$ reactiva (PCR) fue de $20,92 \mathrm{mg} / \mathrm{dl}$. En el estudio de coagulación destacaba un tiempo de protrombina de 58\% (INR 1,47). El resto de las evaluaciones de recuento hematológico, coagulación, electrolitos plasmáticos y bioquímica fueron normales. Se realizó además un VDRL y ELISA para virus de la inmunodeficiencia humana, los que fueron negativos.

Su evaluación neurológica fue complementada con una tomografía axial computada (TAC) de cerebro que no demostró hallazgos patológicos. Mediante una punción lumbar fue obtenido un LCR de aspecto turbio, con un estudio citoquímico en que destacó una proteinorraquia de $7,8 \mathrm{~g} / 1$, glucorraquia menor a $2 \mathrm{mg} / \mathrm{dl}$ y un recuento
Universidad Austral de Chile (EK, GF, RC, RP, VA, MC). Hospital Clínico Regional Valdivia, Chile (CC, RH).

Conflicto de interés: no existe.

Fuente de financiamiento: Instituto de Medicina. Universidad Austral de Chile.

Recibido: 11 de diciembre de 2012 Aceptado: 2 de septiembre de 2013

Correspondencia a:

Erica Koch $\mathrm{H}$.

erica.koch.hein@gmail.com 
celular de 5.368 leucocitos $/ \mathrm{mm}^{3}$, con $92 \%$ de PMN.

Por el cuadro clínico y los hallazgos de laboratorio se diagnosticó una meningitis bacteriana aguda, iniciándose tratamiento empírico con ceftriaxona ( $2 \mathrm{~g} \mathrm{c} / 12 \mathrm{~h})$ y dexametasona (10 mg c/6 h) vía iv. La tinción de Gram del LCR informó la presencia de abundantes cocáceas grampositivas.

La paciente fue ingresada a la Unidad de Cuidados Intensivos (UCI), presentando en las siguientes horas un cuadro de shock séptico, que requirió el uso de aminas vasoactivas y conexión a ventilación mecánica invasora (VMI) para su estabilización. Notablemente, se observó que sólo a partir de las $48 \mathrm{~h}$ del ingreso la paciente presentó fiebre ( $\mathrm{T}^{\circ}$ máxima $38,9^{\circ} \mathrm{C}$ ), persistiendo con compromiso de conciencia. Evolucionó a la mejoría del shock séptico, por lo que se suspendió la sedación para su desconexión de VMI, posterior a lo cual se observó con agitación psicomotora, sin otras manifestaciones neurológicas. En forma complementaria se realizó un EEG, que identificó la presencia de una lentitud generalizada continua, sin identificar una actividad epileptiforme.

El LCR se sembró en agar sangre, agar chocolate y caldo tioglicolato y se incubó a $37^{\circ} \mathrm{C}$ en atmósfera de aerobiosis y microaerofilia. A las $48 \mathrm{~h}$ de incubación en agar sangre y aerobiosis se observó el desarrollo de colonias pequeñas, transparentes, de $1 \mathrm{~mm}$ de diámetro, con una pequeña $\beta$ hemólisis. A la tinción de Gram de la colonia se observaron cocáceas grampositivas agrupadas en cadenas cortas o aisladas. En las pruebas bioquímicas se presentó como catalasa, bilis esculina, $\mathrm{NaCl}$ 6,5\% e hidrólisis de hipurato negativas.

El cultivo de LCR fue informado como $S$. suis serotipo 2 , sensible a penicilina, ampicilina, cefotaxima, ceftriaxona, levofloxacina, eritromicina, clindamicina, linezolid, vancomicina y tetraciclina. Los cultivos obtenidos de orina, secreción bronquial y sangre no demostraron desarrollo bacteriano. La identificación y estudio de susceptibilidad fueron realizados por los sistemas automatizados Vitek ${ }^{\circledR}$ (bioMérieux) y MicroScan ${ }^{\circledR}$.

A los seis días de tratamiento antibacteriano persistía febril y deliriosa, por lo que se solicitaron nuevos cultivos (LCR, hemocultivos, secreción bronquial, catéter venoso central y orina); en todos ellos no hubo desarrollo microbiano. La fiebre fue interpretada como secundaria a fármacos, cediendo posterior a la suspensión de haloperidol.

A los 10 días de tratamiento antibacteriano se encontraba vigil, conectada al medio, aunque con episodios de desorientación ocasional, sin fiebre. Se mantuvo un total de 13 días en VMI, por poca tolerancia a la ventilación espontánea. El tratamiento antimicrobiano se mantuvo por un total de 14 días, con evolución clínica y de laboratorio favorables. La paciente fue evaluada por neurología en que se descartó la existencia de signos de focalización neurológica al alta.
Retrospectivamente se indagó en sus antecedentes epidemiológicos, constatándose que la paciente criaba cerdos y estaba a cargo directamente de su cuidado.

\section{Caso clínico 2}

Varón de 48 años de edad, con antecedentes de consumo excesivo de alcohol, de origen rural. Consultó en el hospital de su localidad por un cuadro de $24 \mathrm{~h}$ de evolución con náuseas y vómitos, a los que se había agregado cefalea intensa y sensación febril. Al examen físico presentaba signos meníngeos, por lo que fue derivado a nuestro hospital con sospecha de meningitis bacteriana aguda. Ingresó al Servicio de Urgencia en buenas condiciones, afebril y normotenso. Al examen físico destacaban nistagmus rotatorio a derecha y la presencia de signos meníngeos; no se describieron otros hallazgos patológicos.

En el estudio de laboratorio destacaba una leucocitosis de 16.850 céls $/ \mathrm{mm}^{3}$, con neutrófilos $91,8 \%$ y una PCR de 32,12 mg/dl. Otros parámetros hematológicos, bioquímicos y de coagulación se encontraban dentro de rangos normales. Se realizó una punción lumbar en que se obtuvo un LCR de aspecto turbio a presión aumentada. El estudio citoquímico demostró una proteinorraquia de $5,6 \mathrm{~g} / \mathrm{l}$, glucorraquia no detectable y 2.300 leucocitos/ $\mathrm{mm}^{3}$, con $95 \%$ de PMN. La tinción de Gram fue informada como diplococos lanceolados grampositivos. El cultivo y los métodos de identificación microbiológicos fueron similares a los utilizados en el primer caso clínico.

Se diagnosticó una meningitis aguda bacteriana y se inició tratamiento empírico con ceftriaxona $(2 \mathrm{~g} \mathrm{c} / 12 \mathrm{~h})$ y dexametasona (10 mg c/6 h) vía i.v.

El segundo día de hospitalización presentó una agitación psicomotora y alucinaciones, con poca respuesta a risperidona y haloperidol. Se interpretó como un posible síndrome de deprivación alcohólica, manejándose con clordiazepóxido y tiamina. Al sexto día de evolución el paciente se encontraba tranquilo, orientado y asintomático.

Dentro del estudio microbiológico, en el cultivo de LCR se aisló $S$. suis serotipo 2, sensible a ceftriaxona, eritromicina, penicilina $\mathrm{G}$ y cotrimoxazol.

Al sexto día de hospitalización se realizó una TAC cerebral de control en que no se observaron hallazgos patológicos.

El paciente fue trasladado a su hospital de origen al octavo día de evolución clínica, en buenas condiciones y sin hallazgos de focalización neurológica. Completó 14 días de tratamiento con ceftriaxona. En el seguimiento posterior, tres meses después del alta, el paciente refería mareos y se constató una hipoacusia bilateral.

Retrospectivamente se rescató el antecedente epidemiológico de que el paciente criaba cerdos. 


\section{Discusión}

Streptococcus suis es un patógeno zoonótico emergente, que puede causar infecciones sistémicas graves en humanos. Los casos aquí presentados son, según nuestro conocimiento, los primeros comunicados en Chile.

Streptococcus suis es un anaerobio facultativo grampositivo. El principal reservorio son los cerdos, en los que coloniza el tracto respiratorio superior. En el ganado porcino, la infección es habitualmente asintomática ${ }^{2}$, pero puede manifestarse clínicamente en estos animales como sepsis, meningitis, artritis y neumonía ${ }^{8}$.

Del punto de vista de su clasificación microbiológica, se han identificado 35 serotipos, en base a los polisacáridos capsulares. El serotipo 2 ha sido el más frecuentemente asociado a patogenicidad, con excepción de dos casos causados por el serotipo $1^{2,9}$, uno por el serotipo $4^{10,11}$, un caso de septicemia por el serotipo $14^{12}$, y otro caso de septicemia causado por el serotipo $16^{13}$. Se han propuesto distintos mecanismos de virulencia; entre ellos destaca el polisacárido capsular (considerado un importante factor antifagocítico), la proteína suilisina (hemolisina que modularía la interacción de $S$. suis con distintas células del hospedero) y modificaciones en componentes de la pared celular, como son la $\mathrm{N}$-deacetilación del peptidoglicano y D-alaninación del ácido lipoteicoico ${ }^{14}$. Estos factores interferirían con la acción de las células presentadores de antígenos y con su destrucción mediada por el complemento ${ }^{14}$. También se han estudiado "islotes genómicos", los cuales constituyen un conjunto de genes que codifican para reconocidos factores de virulencia (por ejemplo la suilisina $)^{15}$. Estos islotes genómicos pueden ser adquiridos por cepas de $S$. suis, otorgándoles mayor patogenicidad. Por ejemplo, islotes genómicos específicos fueron analizados en la cepa "ST7" (por sus siglas en inglés "single sequence type”), responsable del brote epidémico en China el año 2005, y fueron asociados a la inducción de producción masiva de citoquinas inflamatorias ${ }^{16,17}$. Se ha descrito también la capacidad de transmisión horizontal de material genético en transposones que codifican mecanismos de virulencia y resistencia, los que permiten la emergencia y diseminación de clones exitosos. Uno de los mecanismos de resistencia a tetraciclinas se puede transmitir de esta manera, lo que explicaría la diseminación de clones resistentes, favorecida por la utilización de estos antimicrobianos en la crianza de cerdos en China ${ }^{11,16,17}$.

Esta zoonosis tiene un riesgo ocupacional conocido. Si bien en la mayoría de los reportes de casos se indica el antecedente epidemiológico de exposición laboral al ganado porcino, en una revisión retrospectiva de 21 casos ocurridos en Hong Kong, sólo en 24\% se reportó exposición ocupacional ${ }^{18}$.

La infección a humanos se transmite a través del contacto directo con cerdos portadores o carne contaminada con $S$. suis, a través de lesiones en piel, mucosa oral o de la cavidad nasal ${ }^{2,19}$. Cabe destacar que si la carne de cerdos infectados o colonizados se encuentra adecuadamente cocida, constituiría un bajo riesgo de transmisión a humanos ${ }^{20}$. Si bien esta infección suele presentarse en personas inmunocompetentes, se han descrito casos en individuos inmunocomprometidos, especialmente esplenectomizados ${ }^{21}$. Otros factores de riesgo reportados son la diabetes mellitus, alcoholismo, neoplasias y enfermedades cardíacas estructurales ${ }^{6,9,22}$.

No se ha determinado la prevalencia y trascendencia de la portación asintomática en humanos ${ }^{6}$. Al respecto, un estudio de seroprevalencia realizado en Holanda, reveló presencia de anticuerpos contra S. suis serotipo 2 en $6 \%$ de un grupo de 102 veterinarios, y en $1 \%$ de 191 criadores de $\operatorname{cerdos}^{6,23}$. Un reporte realizado en Alemania sobre portación nasofaríngea, realizado en un grupo de 132 individuos con exposición laboral recurrente (carniceros, empleados procesadores de carne), demostró que 5,3\% eran portadores; en cambio, no se encontraron portadores en el grupo control (130 individuos $)^{6,24}$.

Las infecciones por $S$. suis se manifiestan como una infección sistémica, que puede afectar múltiples órganos y sistemas ${ }^{6}$. La meningitis aguda purulenta es la manifestación clínica más frecuente ${ }^{2,4,6}$, y suele presentarse luego de un breve pródromo "tipo-influenza"19. Otras manifestaciones descritas incluyen sepsis, endocarditis, neumonía, artritis, shock séptico, espondilo-discitis, uveítis o más recientemente aneurismas micóticos ${ }^{25}$. Los signos y síntomas clínicos de la meningitis por S. suis son similares a los de otras meningitis bacterianas, incluyendo cefalea, fiebre, vómitos y meningismo ${ }^{6}$, aunque también se han descrito algunas características distintivas, particularmente la pérdida auditiva y ataxia ${ }^{2-4,26}$. La hipoacusia se reporta hasta en $50 \%$ de los pacientes al momento de presentación, o algunos días después ${ }^{6,22}$. En el curso de los cuadros de presentación más grave, como en los casos de shock séptico/tóxico, pueden presentarse signos de hemorragia subcutánea (lesión en piel típicamente purpúrica, evidenciándose a veces cambios gangrenosos), coagulación intravascular diseminada, falla renal aguda y síndrome de distrés respiratorio ${ }^{2,6,27}$.

La mortalidad de la meningitis por $S$. suis es baja ( 5 a $9 \%$ ), pero, en caso de shock séptico, se describe cifras incluso mayores a $80 \% 0^{2,27}$. En los pacientes esplenectomizados, se ha descrito una mortalidad de aproximadamente $80 \%$, por lo que se ha sugerido que estos individuos se abstengan de trabajos en contacto con cerdos o procesamiento de su carne ${ }^{21}$. En más de $50 \%$ de los casos pueden persistir secuelas neurológicas (hipoacusia, ataxia, lesión vestibular). La pérdida auditiva es de tipo neurosensorial y puede ser profunda, aunque algunos pacientes mejoran con el tiempo ${ }^{6}$.

La sospecha diagnóstica de infección por $S$. suis se 
basa en los hallazgos clínicos, antecedentes epidemiológicos y exámenes de laboratorio de rutina. Los pacientes infectados con S. suis por lo general presentan leucocitosis (13.000 a 26.000 céls $/ \mathrm{mm}^{3}$ ) con predominio de neutrófilos (81 a 95\%), PCR elevada (13 a $23 \mathrm{mg} / \mathrm{dl}$ ), y ocasionalmente elevación de las transaminasas hepáticas. El LCR usualmente es turbio, con pleocitosis de predominio polimorfonuclear y glucorraquia baja ${ }^{2}$.

La confirmación etiológica del diagnóstico es microbiológica. Como ya ha sido mencionado, S. suis es una cocácea grampositiva, que puede observarse como cocáceas aisladas, en pares o cadenas cortas. Se cultiva con técnicas microbiológicas estándares, observándose $\alpha$ hemólisis y ausencia de $\beta$ hemólisis en agar sangre de cordero. Se identifica mediante técnicas bioquímicas, entre ellas catalasa negativa, resistencia a optoquina, acetilmetilcarbinol (Voges-Proskauer) negativa, trehalosa positiva y ausencia de crecimiento en cloruro de sodio al $6,5 \%{ }^{1,2,27,28}$. La posibilidad de una $\beta$ hemólisis, como ocurrió en nuestro primer caso, también es un fenómeno descrito, por lo cuál debe ser tomado en cuenta durante el proceso diagnóstico ${ }^{28}$. Existen sistemas comerciales que pueden ser usados, tales como el API Strep ${ }^{\circledR}$ y Vitek $2{ }^{6,27}$. Con los cultivos tradicionales, $S$. suis puede ser subdiagnosticado o identificado erróneamente como otras especies de Streptococcus a hemolíticos, como Streptococcus del grupo viridans, Enterococcus faecalis, Aerococcus viridans o incluso Streptococcus pneumo$n_{i a e^{6}}$. La técnica molecular RPC específica para S.suis serotipo 2 se ha implementado y ha demostrado aumentar la detección de infección humana por S. suis s,6,27 $^{2}$.

El inicio de tratamiento antimicrobiano no debe ser demorado, recomendándose ceftriaxona como tratamiento empírico ${ }^{6}$. El esquema consistente en ceftriaxona $2 \mathrm{~g}$ c/12 h por 14 días ha mostrado una tasa de curación de $97 \%{ }^{6,26}$. Se ha descrito resistencia a tetraciclina en $83,2 \%$; a eritromicina en $20 \%$ y a cloranfenicol en $3,3 \%{ }^{6,26}$. Resistencia a penicilina se ha descrito sólo en un caso de infección humana ${ }^{29}$.

El uso de dexametasona como adyuvante para reducir secuelas neurológicas y mortalidad es controversial ${ }^{6}$. Sin embargo, en un estudio randomizado doble ciego realizado en Vietnam, el uso de dexametasona $(0,4 \mathrm{mg} /$ $\mathrm{kg}$, cada 12 hrs, por 4 días) como adyuvante mostró una reducción significativa del riesgo de muerte entre uno y seis meses, en pacientes con meningitis bacteriana aguda por S.suis ${ }^{6,26,30}$. Además, en el grupo que recibió dexa- metasona, $12,3 \%$ presentaron hipoacusia como secuela, versus $37,7 \%$ en el grupo placebo ${ }^{26,30}$.

En el presente, no existe vacuna contra S.suis para humanos. Por esto, creemos importante educar a la población en riesgo respecto a medidas preventivas simples, tales como el uso de guantes durante el procesamiento de carne de cerdo, y lavado posterior de manos, ya que las heridas cutáneas son puertas de entrada reconocidas. Dado que esta infección también se transmite a través de heridas en la mucosa oral, se recomienda ingerir carne de cerdo bien cocida, considerando que el $S$. suis puede sobrevivir hasta $10 \mathrm{~min}$ a $60^{\circ} \mathrm{C}$ y dos horas a $50^{\circ} \mathrm{C}^{2}$.

Aunque la incidencia de esta zoonosis es baja, el rescate de antecedentes epidemiológicos en la anamnesis es vital para sospechar este agente etiológico como parte del diagnóstico diferencial en pacientes expuestos a ganado porcino o su carne cruda.

En vista de los casos presentados, creemos importante que esta entidad deba ser considerada en el diagnóstico diferencial de los cuadros sépticos y considerar el antecedente de exposición laboral al ganado porcino como un elemento para su sospecha clínica.

\section{Resumen}

La infección humana por Streptococcus suis es una zoonosis con riesgo ocupacional conocido, siendo la meningitis aguda su manifestación clínica más frecuente. Se presentan los dos primeros casos en Chile. Primer caso: Mujer de 54 años con un cuadro de cefalea y vómitos, confusión y signos meníngeos. Evolucionó con un shock séptico. Segundo caso: Varón de 48 años, refirió cefalea y vómitos. Presentó signos meníngeos al examen físico. En ambos casos en la tinción de Gram de líquido cefalorraquídeo (LCR) se observaron cocáceas grampositivas. Fueron tratados con ceftriaxona y dexametasona. El cultivo de LCR fue positivo en ambos casos para $S$. suis serotipo 2. En los dos pacientes la evolución clínica fue favorable, sin alteraciones neurológicas al alta. En ambos casos se obtuvo en forma retrospectiva el antecedente de realizar labores de crianza de ganado porcino. Se destaca la importancia de investigar los antecedentes epidemiológicos para sospechar este agente etiológico en meningitis aguda. Se debe considerar el riesgo ocupacional en una posible infección por este patógeno humano emergente y educar a la población en riesgo sobre medidas preventivas simples. 


\section{Referencias bibliográficas}

1.- Nagel A, Manias V, Busquets N, Sniadowsky S, Anzardi J, Méndez Ede L. Meningitis por Streptococcus suis en un paciente inmunocompetente. Rev Argent Microbiol 2008; 40: 158-60.

2.- Lun Z R, Wang Q P, Chen X G, Li A X, Zhu X Q. Streptococcus suis: an emerging zoonotic pathogen. Lancet Infect Dis 2007; 7: 201-9.

3.- Geffner Sclarsky D E, Moreno Muñoz R, Campillo Alpera M S, Pardo Serrano F J, Gómez Gómez A, Martínez-Lozano M D. Meningitis por Streptococcus suis. An Med Interna 2001; 18: 317-8.

4.- Fernández-Ferro J, López-González F J, Pardo F, Pías-Peleteiro J M. Meningitis aguda por Streptococcus suis en una criadora de cerdos. Enferm Infecc Microbiol Clin 2011; 29: 396-7.

5.- Perch B, Kristjansen P, Skadhauge K. Group R streptococci pathogenic for man. Two cases of meningitis and one fatal case of sepsis. Acta Pathol Microbiol Scand 1968; 74: 69-76.

6.- Wertheim H F, Nghia H D, Taylor W, Schultsz C. Streptococcus suis: an emerging human pathogen. Clin Infect Dis 2009; 48: 617-25.

7.- $\quad$ Lopreto C, Lopardo H A, Bardi M C, Gottschalk M. Meningitis primaria por Streptococcus suis: primer caso en humanos descrito en América Latina. Enferm Infecc Microbiol Clin 2005; 23: 110.

8.- Jofré L, Perret C, Abarca K, Solari V, Olivares R, López del P. J. Recomendaciones para el manejo de mordeduras ocasionadas por animales. Rev Chilena Infectol 2006; 23 : 20-34.

9.- Vilaichone RK, Vilaichone W, Nunthapisud P, Wilde H. Streptococcus suis infection in Thailand. J Med Assoc Thai 2002; 85 Suppl 1: S 109-17.
10.- Arends J P, Zanen H C. Meningitis caused by Sreptococcus suis in humans. Rev Infec Dis 1988; 10: 131-7.

11.- Ye C, Bai X, Zhang J, Jing H, Zheng H, $\mathrm{Du} \mathrm{H}$, et al. Spread of Streptococcus suis sequence type 7, China. Emerg Infect Dis 2008; 14: 787-91.

12.- Watkins E J, Brooksby P, Schweiger M S, Enright S M. Septicaemia in a pig-farm worker. Lancet 2001; 357: 38 .

13.- Nghia H D, Hoa N T, Linh le D, Campbell J, Diep T S, Chau N V et al. Human case of Streptococcus suis serotype 16 infection. Emerg Infect Dis 2008; 14: 155-7.

14.- Lecours M P, Gottschalk M, Houde M, Lemire P, Fittipaldi N, Segura M, et al. Critical role for Streptococcus suis cell wall modifications and suilysin in resistance to complement-dependent killing by dendritic cells. J Infect Dis 2011; 204: 919-29.

15.- Ye C, Zheng H, Zhang J, Jing H, Wang L, Xiong $\mathrm{Y}$, et al. Clinical, experimental, and genomic differences between intermediately pathogenic, highly pathogenic, and epidemic Streptococcus suis. J Infect Dis. 2009; 199: 97-107.

16.- Zheng X, Zheng H, Lan R, Ye C, Wang Y, Zhang J, et al. Identification of genes and genomic islands correlated with high pathogenicity in Streptococcus suis using whole genome tiling microarrays. PLoS One 2011; 6: e17987.

17.- Segura M. Streptococcus suis: an emerging human threat. J Infect Dis 2009; 199: 4-6.

18.- Ma E, Chung P H, So T, Wong L, Choi K M, Cheung D T, et al. Streptococcus suis infection in Hong Kong: an emerging infectious disease? Epidemiol Infect 2008; 136: 1691-7.

19.- Francois B, Gissot V, Ploy M C, Vignon P. Recurrent septic shock due to Streptococcus suis. J Clin Microbiol 1998; 36: 2395.

20.- Du Y P, Qian W J, Xu G B. Investigation on 8 human cases with meningitis caused by Streptococcus suis type 2. Chin J Prev Med 2000; 34: 305.
21.- Gallagher F. Streptococcus suis infection and splenectomy. Lancet 2001; 357: 1129-30.

22.- Huang Y T, Teng L J, Ho S W, Hsueh P R. Streptococcus suis infection. J Microbiol Immunol Infect 2005; 38: 306-13.

23.- Elbers A R, Vecht U, Osterhaus A D, Groen J, Wisselink H J, Diepersloot R J, et al. Low prevalence of antibodies against the zoonotic agents Brucella abortus, Leptospira spp., Streptococcus suis serotype II, hantavirus, and lymphocytic choriomeningitis virus among veterinarians and pig farmers in the southern part of The Netherlands. Vet Q 1999; 21: 50-4.

24.- Strangmann E, Fröleke H, Kohse K P. Septic shock caused by Streptococcus suis: case report and investigation of a risk group. Int J Hyg Environ Health 2002; 205: 385-92.

25.- Laohapensang K, Rutherford R B, Arworn S. Mycotic abdominal aortic aneurysm due to Streptococcus suis: a case report. Surg Infect (Larchmt) 2010, 11: 179-81.

26.- Mai N T, Hoa N T, Nga T V, Linh le D, Chau T T, Sinh D X, et al. Streptococcus suis meningitis in adults in Vietnam. Clin Infect Dis 2008; 46: 659-67.

27.- Yu H, Jing H, Chen Z, Zheng H, Zhu X, Wang H, et al. Human Streptococcus suis outbreak, Sichuan, China. Emerg Infect Dis 2006; 12: 914-20.

28.- Alarcón P. Retrato microbiológico de Streptococcus suis. Rev Chilena Infectol 2012; 29: 541-2.

29.- Shneerson J M, Chattopadhyay B, Murphy M F, Fawcett I W. Permanent perceptive deafness due to Streptococcus suis type-II infection. J Laryngol Otol 1980; 94 : 425-7.

30.- Nguyen T H, Tran T H, Thwaites G, Ly V C, Dinh X S, Ho Dang T N, et al. Dexamethasone in vietnamese adolescents and adults with bacterial meningitis. N Engl J Med 2007; 357 : 2431-40. 